This is the final peer-reviewed accepted manuscript of:

LC-MS/MS and volumetric absorptive microsampling for quantitative bioanalysis of cathinone analogues in dried urine, plasma and oral fluid samples

Laura Mercolini*, Michele Protti, Maria C. Catapano, James Rudge, Angelo E. Sberna

Journal of Pharmaceutical and Biomedical Analysis 123 (2016) 186-194

The final published version is available online at:

https://doi.org/10.1016/j.jpba.2016.02.015

Rights / License:

The terms and conditions for the reuse of this version of the manuscript are specified in the publishing policy. For all terms of use and more information see the publisher's website.

This item was downloaded from IRIS Università di Bologna (https://cris.unibo.it/)

When citing, please refer to the published version. 


\section{LC-MS/MS and volumetric absorptive microsampling for quantitative bioanalysis of cathinone analogues in dried urine, plasma and oral fluid samples}

Laura Mercolini $^{a, *}$, Michele Protti $^{a}$, Maria C. Catapano ${ }^{a}$, James Rudge $^{b}$, Angelo E. Sberna $^{c}$

a Laboratory of Pharmaco-Toxicological Analysis, Department of Pharmacy and Biotechnology

(FaBiT), Alma Mater Studiorum-University of Bologna, Via Belmeloro 6, 40126 Bologna, Italy

${ }^{\mathrm{b}}$ Neoteryx LLC, 421 Amapola Avenue, 90501 Torrance, CA, USA

' Sport Medicine, Enna Local Health Unit, Viale A. Diaz 7, 94100 Enna, Italy

* Corresponding Author:

Prof. Dr. Laura Mercolini

Research Group of Pharmaco-Toxicological Analysis (PTA Lab)

Department of Pharmacy and Biotechnology (FaBiT)

Alma Mater Studiorum - University of Bologna

Via Belmeloro 6, 40126 Bologna, Italy

Tel.: +390512099726

e-mail: laura.mercolini@unibo.it

This item was downloaded from IRIS Università di Bologna (https://cris.unibo.it/)

When citing, please refer to the published version. 


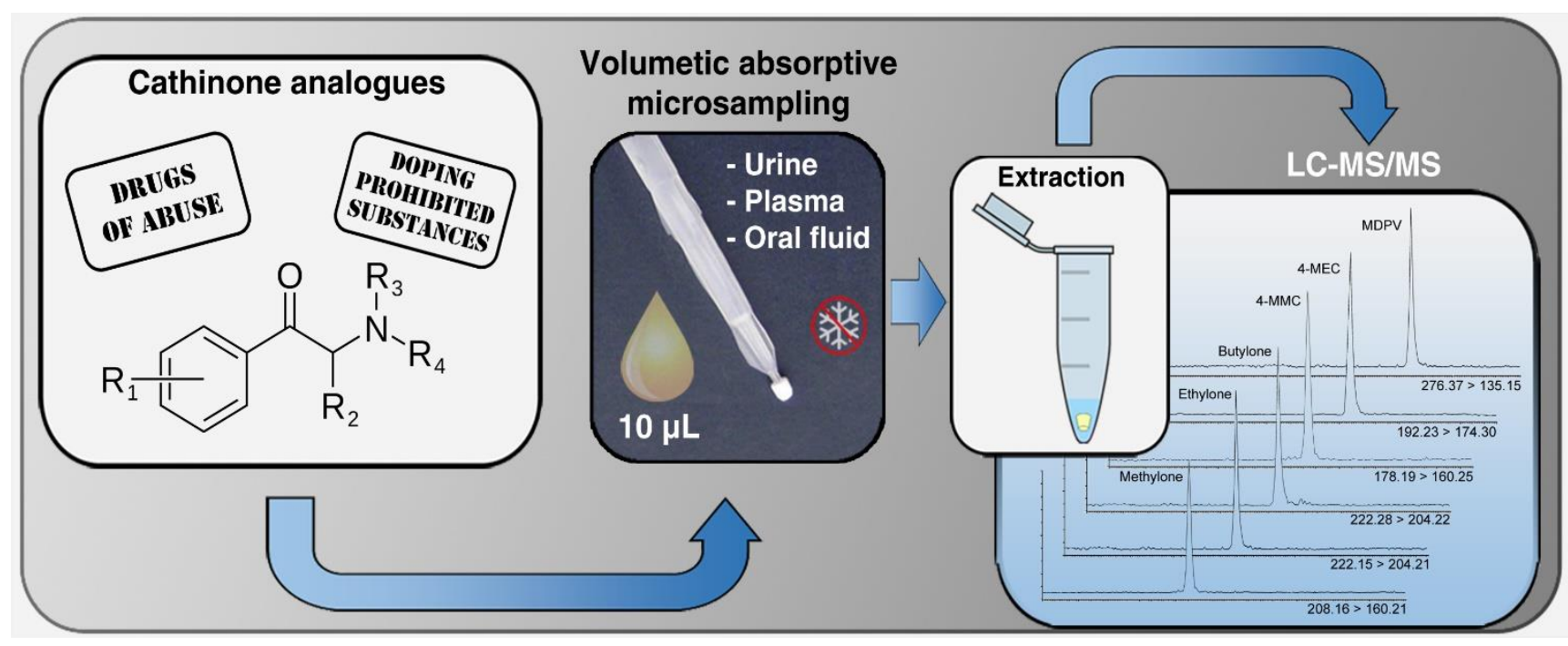

This item was downloaded from IRIS Università di Bologna (https://cris.unibo.it/)

When citing, please refer to the published version. 


\section{ABSTRACT}

In the last few years, several cathinone analogues have appeared on the illicit drug market and proposed as an alternative to already known stimulants in several recreational settings. The World Anti-Doping Agency classified the synthetic cathinones in the Prohibited List as specified stimulants, banned in sport competitions. We developed and validated an LC-MS/MS method for the analysis of methylone, ethylone, butylone, mephedrone, 4-methylethcathinone and 3,4-methylenedioxypyrovalerone in dried urine, plasma and oral fluid samples. Volumetric absorptive microsampling has been employed as a miniaturised sampling technique for collecting dried biological samples. Chromatographic analysis was carried out on a C18 reversed phase column with a mobile phase composed of formic acid in a water/acetonitrile mixture, by using a triple quadrupole mass analyzer. The main parameters of the volumetric absorptive microsampling procedure were investigated and the method was fully validated with satisfactory results in terms of linearity, precision, absolute recovery, matrix effects, selectivity and stability. The method was successfully applied to real VAMS samples collected from cathinones users. The biosampling strategy via volumetric absorptive microsampling for urine, plasma and oral fluid could provide reliable information, with a future perspective of implementation for forensic cases as well as for sport drug testing.

Keywords: Cathinone analogues; Dried biological matrices; Volumetric absorptive microsampling; LC-MS/MS; Quantitative bioanalysis.

This item was downloaded from IRIS Università di Bologna (https://cris.unibo.it/) 


\section{INTRODUCTION}

Over the past 10 years numerous cathinone analogues have emerged and supplied the illicit market, in addition to classical stimulant drugs, such as amphetamines or cocaine [1]. Cathinone (Fig. 1a), precursor of these substances, derives from Catha edulis leaves and has psychoactive properties similar to those of amphetamines. Cathinone analogues are typically sold as "bath salts" or "fertilizers" to bypass drug law enforcement, as the presence of psychoactive compounds is never stated and the label usually indicates products "not intended for human consumption" [2]. Since 2010, several synthetic cathinones, including methylone (1- (1,3-benzodioxol-5-il2- (methylamine) methyl-1-one, Fig. 1b), ethylone ((RS) - 1- (1,3-benzodioxol-5-il2- (ethylamine) propan-1-one, Fig. 1c), butylone (1- (1,3-benzodioxol-5-il2- (methylamine) butan-1-one, Fig. 1d), mephedrone ((RS) -2methylamino-1- (4-methylphenyl) propan-1-one, 4-MMC, Fig. 1e), 4-methylethcathinone ((RS) -2ethylamino-1- (4-methylphenyl) propan-1-one, 4-MEC, Fig. 1f) and 3,4methylenedioxypyrovalerone ((RS)-1-(benzo[d][1,3]dioxol-5-yl)-2-(pyrrolidin-1-yl) pentan-1-one, MDPV, Fig. 1g) have been added to the USA schedule of controlled substances [3]. The current knowledge regarding their toxicity is based largely on some case reports and derives from some poison centres and surveys of abusers; sympathomimetic effects (e.g. hypertension, tachycardia, increased incidence of acute myocardial infarction) as well as psychological ones (e.g. aggression, agitation, paranoid delusions) [4] are the most common adverse effects experienced by the abusers. Due to their stimulant properties, cathinone and its synthetic analogues are examples that reflect emerging patterns of drug use among athletes, thus been included in the prohibited list of the World Anti-Doping Agency (WADA) and classified as specified stimulants banned in sport competitions [5].

This item was downloaded from IRIS Università di Bologna (https://cris.unibo.it/)

When citing, please refer to the published version. 
In recent times many efforts have been made by researchers to enhance and simplify drug testing, in order to provide high-throughput reliable results. However, crucial issues are still unsolved within sampling procedures and analysis, including the limitations inherent to biological fluids of choice, concerning forensic cases and doping control activities. The use of dried matrix spots, mainly dried blood spots (DBSs) has recently drew considerable attention within quantitative bioanalysis of psychoactive compounds [6], driven by its advantages over conventional "in-tube" sampling: reduced sample volumes, simplified collection, increased analyte stability, no requirement for frozen storage and refrigerated transport, cost savings [7-12]. In addition to these advantages, the volumetric absorptive microsampling (VAMS) approach represents an innovative attractive strategy able also to collect accurate volumes of blood: the VAMS device was in fact designed for blood collection [13], but it could also be suitable for other biological matrices such as urine, plasma and oral fluid across a wide range of sampling conditions.

So far, a few methods, mainly based on gas chromatography and liquid chromatography coupled to mass spectrometry (GC-MS or LC-MS), are present in the scientific literature for the analysis of one or more synthetic cathinones, in powder or seized samples [14-19], whole blood [20,21], plasma or serum $[22,23]$, urine $[20,24,25]$, oral fluid $[26,27]$ and DBSs [28].

As with most designer drugs, there is a lack of phamacokinetic controlled studies on humans thus, as concerns expected concentrations, the data available in the literature are limited and involve case reports about intoxications, driving under the influence (DUI) screenings and post-mortem analysis. Although such values cannot be considered as references, the concentrations of cathinone analogues ranged from 0.03 to $5.1 \mu \mathrm{g} \mathrm{mL}^{-1}$ in blood/plasma, from 0.03 to $68 \mu \mathrm{g} \mathrm{mL}^{-1}$ in urine, from 20 to $470 \mathrm{ng} \mathrm{mL}^{-1}$ in oral fluid [22-32].

This item was downloaded from IRIS Università di Bologna (https://cris.unibo.it/)

When citing, please refer to the published version. 
The present study is the first one describing a new combined VAMS and LC-MS/MS methodology as a simple, feasible and reliable approach to determine the main synthetic cathinones in dried urine, plasma and oral fluid samples. VAMS process parameters, such as exposure time, drying time, temperature, humidity and light exposure, are investigated for biological matrices other than blood (urine, plasma and oral fluid), in order to develop effective and standardised protocols. Therefore, the novel miniaturised sampling approach by means of VAMS described in this paper represents a significant improvement in the field of drug quantitative bioanalysis, for the reliable assessment of these synthetic illicit drugs that are also prohibited substances in sport competitions.

This item was downloaded from IRIS Università di Bologna (https://cris.unibo.it/) 
<smiles>CC(N)C(=O)c1ccccc1</smiles>

a - Cathinone<smiles>CN[C@@H](C)C(=O)c1ccc2c(c1)OCO2</smiles>

b - Methylone<smiles>CCC(NC)C(=O)c1ccc2c(c1)OCO2</smiles>
d - Butylone<smiles>CCN[C@@H](C)C(=O)c1ccc2c(c1)OCO2</smiles>

$$
\text { c - Ethylone }
$$<smiles>CN[C@@H](C)C(=O)c1ccc(C)cc1</smiles>

$$
\text { e - 4-MMC }
$$<smiles>CCNC(C)C(=O)c1ccc(C)cc1</smiles>

f - 4-MEC<smiles>CCCC(C(=O)c1ccc2c(c1)OCO2)N1CCCC1</smiles>

g - MDPV

Figure 1 - Chemical structures of (a) cathinone, (b) methylone, (c) ethylone (d) butylone, (e) mephedrone (4-MMC), (f) 4-methylethcathinone (4-MEC), and (g) 3,4-methylenedioxypyrovalerone (MDPV). 


\section{EXPERIMENTAL}

\subsection{Chemicals, solutions and equipment}

Methylone, ethylone, butylone, 4-MMC, 4-MEC and MDPV stock methanolic solutions (1 mg mL-1) were purchased from Cerilliant Corporation (Round Rock, TX, USA). Methylone- $D_{3}$, ethylone- $D_{5}$, butylone- $D_{3}, 4-M M C-D_{3}$ and MDPV-D8 (used as the Internal Standards, ISs) stock methanolic solutions (0.1 $\mathrm{mg} \mathrm{mL}^{-1}$ ) were also from Cerilliant Corporation. HPLC-grade (> 99.8\%) methanol, acetonitrile and 95\% formic acid (FA) were purchased from Sigma-Aldrich (Milan, Italy). Ultrapure water (18.2 $\mathrm{M} \Omega \mathrm{cm}$ ) was obtained by means of a MilliQ apparatus by Millipore (Milford, MA, USA). Analyte and ISs standard solutions were obtained by diluting stock solutions with a mixture of $0.1 \%$ FA in acetonitrile and $0.1 \%$ FA in water (50/50). All solutions were stored protected from light in amber glass vials from Waters (Milford, MA, USA).

VAMS devices were purchased from Neoteryx (Torrance, CA, USA) under the brand name of Mitra ${ }^{\circledR}$.

\subsection{Biological sample collection}

Blood, urine and oral fluid samples, used as "blank" matrices, were obtained from drug-free healthy volunteers, while real samples were from self-reported users and this use for forensic purposes was already authorised at the time of sampling. Blood was collected in glass tubes containing ethylenediaminetetraacetic acid as the anticoagulant and then centrifuged at $4000 \mathrm{rpm}$ for $10 \mathrm{~min}$ at $4^{\circ} \mathrm{C}$; the supernatant (plasma) was stored at $-80^{\circ} \mathrm{C}$ until the analysis.

Urine was collected in glass tubes, subjected to centrifugation at $4000 \mathrm{rpm}$ for $10 \mathrm{~min}$ at $4^{\circ} \mathrm{C}$ and the supernatant was stored at $-80^{\circ} \mathrm{C}$.

This item was downloaded from IRIS Università di Bologna (https://cris.unibo.it/)

When citing, please refer to the published version. 
Neat, unstimulated oral fluid was sampled by means of a disposable plastic pipette. It was put into glass tubes, centrifuged at $4000 \mathrm{rpm}$ for $10 \mathrm{~min}$ at $4^{\circ} \mathrm{C}$, and the clear supernatant was frozen at $80^{\circ} \mathrm{C}$ until the time of the analysis.

\subsection{LC-MS/MS system}

LC apparatus was a Waters Alliance e2695 system with autosampler. Chromatographic separation was performed on a Zorbax C18 $(2.1 \mathrm{~mm} \times 50 \mathrm{~mm}, 3.5 \mu \mathrm{m})$ reversed-phase column (Agilent Technologies; Palo Alto, CA, USA), maintained at room temperature (RT). As mobile phase $0.1 \%$ FA in acetonitrile (Solvent A) and 0.1\% FA in water (Solvent B) were used at a flow rate of $0.3 \mathrm{~mL} \mathrm{~min}^{-}$

1. The two components of the mobile phase were filtered and degassed. The mobile phase gradient programme composition started with a $2 / 98$ Solvent A/Solvent B ratio, linearly ramping up to $20 \%$ of Solvent A over $2 \mathrm{~min}$; this ratio was maintained for $7 \mathrm{~min}$, then ramped down linearly to $2 \%$ of Solvent A over $3 \mathrm{~min}$. The gradient was then changed to the starting conditions over $3 \mathrm{~min}$ and kept constant for $3 \mathrm{~min}$ to re-equilibrate the system. The total run time was $15 \mathrm{~min}$. The autosampler was kept at RT and the injection volume was $10 \mu \mathrm{L}$.

The mass spectrometer was a Waters-Micromass Quattro Micro triple quadrupole, operating in ESI ${ }^{+}$ mode under the following optimised settings: capillary voltage $3.4 \mathrm{kV}$; ion source and desolvation gas (nitrogen) temperature $125^{\circ} \mathrm{C}$ and $350^{\circ} \mathrm{C}$, respectively; desolvation gas (nitrogen) flow rate 900 $\mathrm{L} / \mathrm{h}$; extractor potential $2 \mathrm{~V}$; collision exit potential $1 \mathrm{~V}$. Nitrogen was used as the desolvation gas and argon as the collision one. The precursor ion and the product ions, with dwell time, cone voltage and collision energy, were optimised by direct infusion of each analyte $\left(1 \mu \mathrm{g} \mathrm{m} \mathrm{m}^{-1}\right.$ solution in a

This item was downloaded from IRIS Università di Bologna (https://cris.unibo.it/)

When citing, please refer to the published version. 


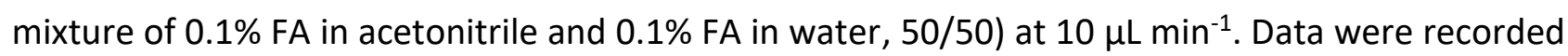
in MRM mode, acquired and processed by using Waters MassLynx 4.1 software.

\subsection{Sampling tests on VAMS device}

Volume tests were carried out to perform matrix absorption experiments by means of a balance with a resolution of $0.01 \mathrm{mg}$. The control protocol for weight measurements was as follows: a $1 \mathrm{~mL}$ aliquot of each matrix (urine, plasma and oral fluid) was placed in a vial, and to determine the weight $(n=6)$ of an accurately pipetted volume of each sample, this initial weight was recorded; $10 \mu \mathrm{L}$ of sample was then removed using a pipette; the vial was finally reweighed. The average density of each matrix was calculated using the formula below:

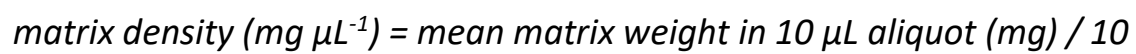

The VAMS protocol for measurements of volume absorbed by VAMS device was as follows: to determine the weight $(n=6)$ of each matrix absorbed by the VAMS tip, the initial weight of a vial containing $1 \mathrm{~mL}$ of each matrix sample was recorded; a VAMS device was carefully dipped into the sample; after filling the tip was removed and the vial reweighed. The volume absorbed on the VAMS tip for each matrix was calculated using the formula below:

mean matrix volume in VAMS tip $(\mu \mathrm{L})=[$ mean matrix weight in VAMS tip $(\mathrm{mg}) /$ mean matrix weight in $10 \mu \mathrm{L}$ aliquot $(\mathrm{mg})] \times 10$

Other sampling parameters were studied on VAMS device, such as exposure time, drying time, temperature, humidity and light exposure.

\subsection{Biological sample preparation}

This item was downloaded from IRIS Università di Bologna (https://cris.unibo.it/)

When citing, please refer to the published version. 


\subsubsection{VAMS procedure}

Calibrators and QC samples were prepared from pooled liquid urine, plasma and oral fluid from healthy volunteers by adding $10 \mu \mathrm{L}$ of analyte and ISs working standard solutions to $90 \mu \mathrm{L}$ of matrix. Dried biological samples were obtained by dipping the tips of VAMS devices into each sample, the tips took between 2 and $4 \mathrm{~s}$ to completely absorb the sample. The VAMS samples were dried for 1 $\mathrm{h}$ at $\mathrm{RT}\left(25^{\circ} \mathrm{C} ; 55 \%\right.$ relative humidity; controlled but not monitored) and then were used immediately or packaged in plastic bags and stored at RT, in the dark and in sealable polyethylene bags containing desiccant packages. The dried VAMS samples were extracted with $500 \mu \mathrm{L}$ of methanol after removing the tip from the device and mixed by means of ultrasound agitation for $15 \mathrm{~min}$ and vortex for $1 \mathrm{~min}$. The extracts were dried under vacuum and then reconstituted with $100 \mu \mathrm{L}$ of a mixture of $0.1 \% \mathrm{FA}$ in acetonitrile and $0.1 \% \mathrm{FA}$ in water (50/50), prior to LC-MS/MS analysis.

\subsubsection{Preparation of comparison wet samples}

Matrix-water samples were processed and analysed for comparison, in order to assess the adherence of the results obtained by means of conventional pre-treatment of wet matrices to those obtained using the novel biosampling approach for dry matrices proposed herein. The samples were prepared by mixing $100 \mu \mathrm{L}$ of spiked blank urine, plasma or oral fluid with an equal volume of water. Protein precipitation was carried out with $500 \mu \mathrm{L}$ of methanol by means of ultrasound agitation for $15 \mathrm{~min}$ and vortexing for $1 \mathrm{~min}$; then the supernatant was dried and reconstituted to the final volume of $1 \mathrm{~mL}$ with a mixture of $0.1 \% \mathrm{FA}$ in acetonitrile and $0.1 \% \mathrm{FA}$ in water (50/50), prior to analysis by LC-MS/MS. Comparison methods on wet samples were concurrently validated in terms of linearity, sensitivity, selectivity and precision at the same concentrations as described for VAMS.

This item was downloaded from IRIS Università di Bologna (https://cris.unibo.it/)

When citing, please refer to the published version. 


\subsection{Method validation}

According to the official guidelines $[33,34]$ the following validation parameters were tested: limit of detection (LOD), limit of quantification (LOQ), linearity, precision, absolute recovery, matrix effect, accuracy, selectivity and stability under different conditions.

\subsubsection{Linearity}

Calibration samples were prepared by adding $10 \mu \mathrm{L}$ of analyte and ISs working standard solutions to blank urine, plasma and oral fluid to obtain spiked concentrations of $10,20,50,100,250,300$, 400 and $500 \mathrm{ng} \mathrm{mL}^{-1}$ for each compound (ISs at constant concentration of $100 \mathrm{ng} \mathrm{mL}^{-1}$ ). The resulting spiked blank samples were subjected to sample preparation procedure and injected into the LCMS/MS system. The procedure was carried out in triplicate for each concentration. The analyte/IS peak area ratios obtained were plotted against the related nominal concentrations and the calibration curves set up by the least-square method. Verification of the quality of fit to the calibration curves was evaluated by comparing back-calculated concentrations to the nominal ones. LOQs and LODs were determined by analysing at least six samples at different concentrations and defined as the lowest concentration which give rise to peaks whose heights are 10 and 3 times the baseline noise, respectively.

\subsubsection{Absolute recovery, precision and matrix effect}

Absolute recovery and precision were evaluated by adding known amounts of the analytes (at three different concentrations, corresponding to the lower limit, a middle point and a high value of each

This item was downloaded from IRIS Università di Bologna (https://cris.unibo.it/)

When citing, please refer to the published version. 
calibration curve) and of ISs (at constant concentration) to blank urine, plasma and oral fluid, then subjecting the mixtures to sample preparation and LC-MS/MS analysis. The analyte and IS absolute peak areas were compared to those of injected standard solutions at the same concentrations and the absolute recovery was calculated.

The assays described above were repeated six times within the same day to obtain intraday precision and six times over six different days to evaluate interday precision, in both cases expressed as percentage relative standard deviation (RSD\%).

IS-corrected matrix effect of dried urine, plasma and oral fluid sampled by VAMS was evaluated on blank sample extracts from 10 different sources, fortified post-extraction by adding known amounts of the analytes at three concentration levels (ISs at constant concentration). Mean analyte/IS peak area ratios of each extract were then compared with analyte/IS peak area ratio from analyte solution prepared in mobile phase and the resulting percentage ratios were calculated.

\subsubsection{Selectivity and stability}

Method selectivity was assessed by individually analysing blank urine, plasma and oral fluid samples from six different healthy volunteers and subjected to pretreatment procedure. The resulting chromatograms were checked for possible endogenous interference and the acceptance criterion was no peak whose signal exceeded $20 \%$ that of the LOQ for the analytes and $5 \%$ for the ISs.

Stability was tested in stock solutions for each analyte by comparing the chromatographic peak area of a standard solution of $25 \mathrm{ng} \mathrm{mL}^{-1}$ diluted from the stock solution stored for 2 months at $-80^{\circ} \mathrm{C}$ with those diluted from just purchased ones $(n=3)$. The stability of stored dried VAMS samples was assessed for each blank matrix spiked with the analytes at $250 \mathrm{ng} \mathrm{mL}^{-1}$ over 7 days at RT, in the dark

This item was downloaded from IRIS Università di Bologna (https://cris.unibo.it/)

When citing, please refer to the published version. 
and in sealable polyethylene bags containing desiccant packages, to reflect normal laboratory storage conditions. After extraction the measured analyte concentrations were compared to those of the same samples extracted and immediately analysed after biosampling and drying.

This item was downloaded from IRIS Università di Bologna (https://cris.unibo.it/)

When citing, please refer to the published version. 


\section{RESULTS AND DISCUSSION}

\subsection{VAMS parameter study}

\subsubsection{Sampled volume test}

The VAMS sampler consists of an absorbent polymeric tip, designed to take up a fixed volume of blood ( 10 $\mu \mathrm{L})$. In this paper for the first time several experiments were carried out to establish the volume absorbed after VAMS tip exposure to biological matrices other than blood and whose density is higher (urine, plasma and oral fluid). Gravimetric analyses showed the calculated densities for urine, plasma and oral fluid in good agreement with those reported in literature (i.e. $1.025 \mathrm{mg} \mathrm{hL}^{-1}$ for plasma, $1.006 \mathrm{mg} \mathrm{hL}^{-1}$ for oral fluid, 1.020 $\mathrm{mg} \mu \mathrm{L}^{-1}$ for urine). The standard deviation (SD) values for mass gravimetric determinations on urine, plasma and oral fluid were between 0.13 and $0.30 \mathrm{mg}$ and between 0.53 and $0.84 \mathrm{mg}$ for pipetted and absorbed volumes, respectively. According to these data and as it can be seen in Table $\mathbf{1}$ and Fig. 2a, the collected volumes are statistically indistinguishable from those pipetted $(\sim 10 \mu \mathrm{L})$, thus showing a good sampling accuracy by means of VAMS devices.

This item was downloaded from IRIS Università di Bologna (https://cris.unibo.it/) 
Table 1- Volume test on VAMS device

\begin{tabular}{|c|c|c|c|c|}
\hline Matrix & $\begin{array}{c}\text { Weight } \\
\text { by pipette } \\
(\mathbf{m g})^{a}\end{array}$ & $\begin{array}{c}\text { Density } \\
\left(\mathbf{m g ~} \boldsymbol{\mu L}^{-1}\right)\end{array}$ & $\begin{array}{c}\text { Weight } \\
\text { by VAMS } \\
(\mathbf{m g})^{a}\end{array}$ & $\begin{array}{c}\text { Volume } \\
\text { in VAMS } \\
(\boldsymbol{\mu L})^{\mathrm{a}}\end{array}$ \\
\hline Urine & $10.12 \pm 0.26$ & 1.012 & $9.80 \pm 0.84$ & $9.68 \pm 0.84$ \\
\hline Plasma & $10.31 \pm 0.13$ & 1.031 & $10.33 \pm 0.53$ & $10.02 \pm 0.53$ \\
\hline Oral fluid & $10.03 \pm 0.30$ & 1.003 & $10.00 \pm 0.58$ & $9.97 \pm 0.58$ \\
\hline
\end{tabular}

${ }^{a}$ Each data point is the average of 6 determinations $\pm S D$

\subsubsection{Exposure time test}

Urine, plasma and oral fluid matrices were sampled until the VAMS tip was completely full $(\sim 2 \mathrm{~s})$, and then the tip was kept in contact with each matrix for additional 2, 6 and $10 \mathrm{~s}$. As one can see from Fig. $\mathbf{2 b}$, the microsampling was volumetrically accurate at $\sim 10 \mu \mathrm{L}$ and there was no additional effect due to longer exposure times with each matrix, thus avoiding the risk of oversampling.

\subsubsection{Drying time, temperature, humidity and light exposure}

A gravimetric analysis on the time required to dry urine, plasma and oral fluid collected by VAMS devices revealed that under both complete ventilation at $\mathrm{RT}\left(25^{\circ} \mathrm{C}\right.$; $55 \%$ humidity) or packaged in a cartridge, the samples are dried within 0.75 and $1 \mathrm{~h}$, respectively. As a final study on volumetric sampling characteristics, matrix collection was carried out under worst sampling conditions of temperature, humidity and light exposure (i.e. $30^{\circ} \mathrm{C},>65 \%$ humidity, full light exposure) and compared with sampling under best conditions $\left(25^{\circ} \mathrm{C}, 55 \%\right.$ humidity, without light exposure). The volumes collected by the VAMS devices under these two distinct sets of conditions were in good agreement (Fig. 2c).

This item was downloaded from IRIS Università di Bologna (https://cris.unibo.it/)

When citing, please refer to the published version. 

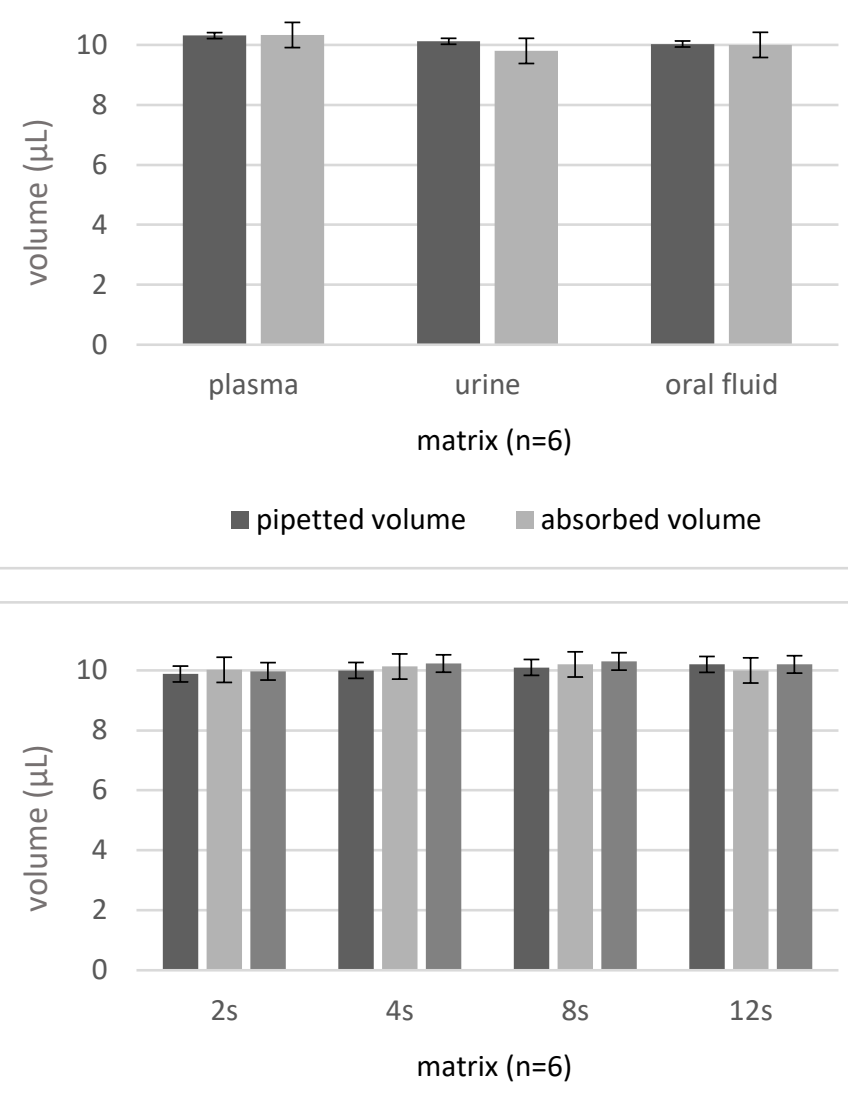

mplasma $\quad$ urine $\quad$ oral fluid

b

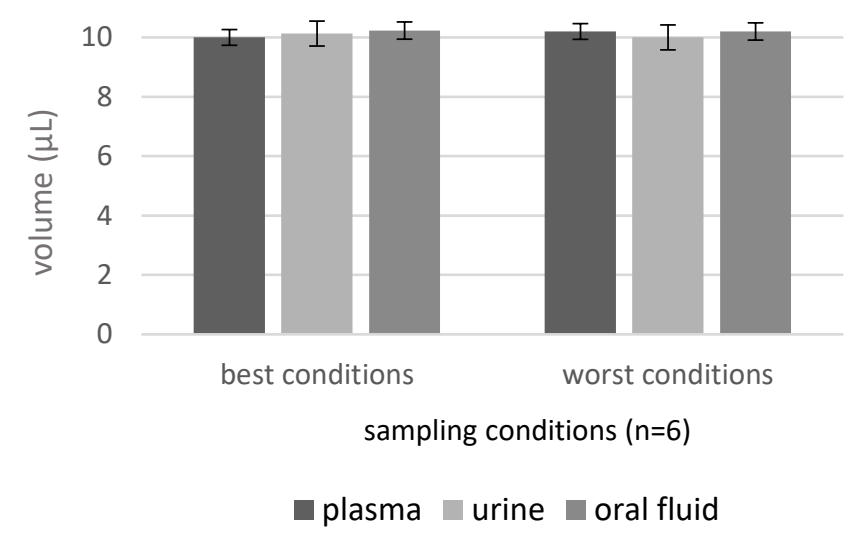

C

Figure 2 - (a) Comparison of pipetted and absorbed volume on VAMS devices for plasma, urine and oral fluid; (b) absorbed volumes on VAMS devices for plasma, urine and oral fluid after several exposure times and (c) combined effect of temperature, humidity and light exposure on volume absorbed by VAMS devices.

This item was downloaded from IRIS Università di Bologna (https://cris.unibo.it/)

When citing, please refer to the published version. 


\subsection{Extraction procedure from VAMS device}

The VAMS approach has been originally designed in order to simplify blood collection (regardless of volumetric hematocrit level) and processing/extraction workflows [13]. Herein the device was tested to sample biological matrices other than blood, i.e. urine, plasma and oral fluid. The use of dried VAMS samples as the biological matrices for synthetic cathinone analysis is the most important innovative aspect of this study.

For this study, ISs have been added to liquid matrix prior to absorption onto the substrate to ensure they are fully associated with matrix components, thus being co-extracted with the analytes as part of the sample. This could provide more detailed information about the performances of the new VAMS sampling.

After sampling on VAMS device, the analytes were desorbed from the tip and several assays were carried out to identify a suitable solvent for this purpose. Pure methanol and acetonitrile, their water mixtures and ethyl acetate were tested; the best results, in terms of both analyte extraction efficiency and matrix effect suppression, were achieved using pure methanol (Fig. 3). Multi-matrix extraction efficiencies for cathinone analogues varied from 70 to $85 \%$ by means of ultrasound ( $15 \mathrm{~min}$ ) combined with vortexing (1 $\mathrm{min}$ ) agitation.

This item was downloaded from IRIS Università di Bologna (https://cris.unibo.it/) 


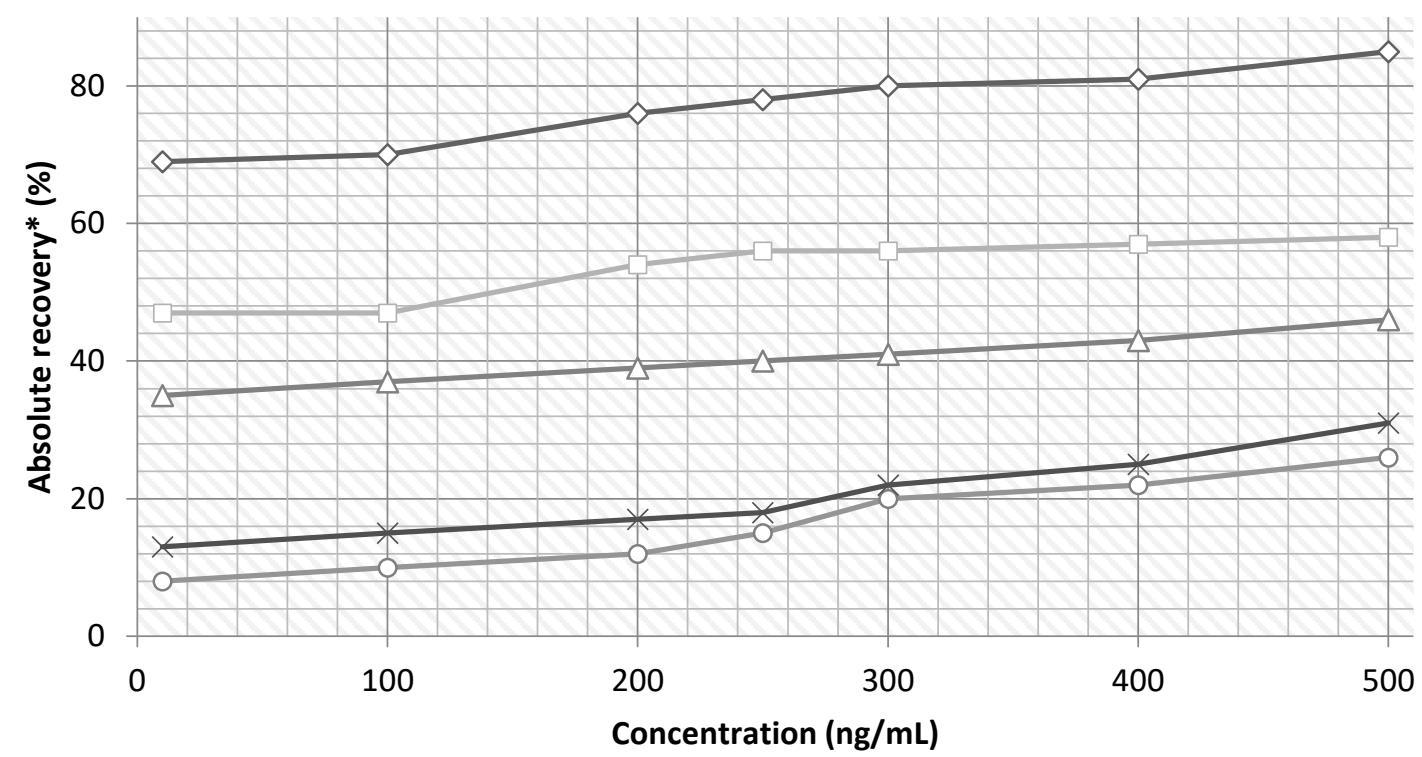

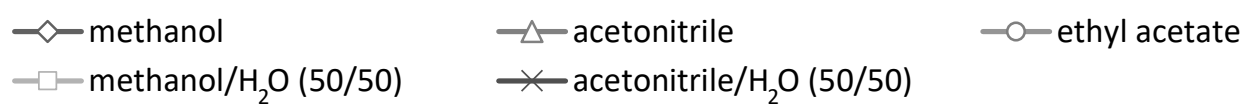

*mean values for the six cathinone analogues in dried urine, plasma and oral fluid samples

Figure 3 - Solvent extraction efficiency for cathinone analogues from dried matrices on VAMS devices. 


\subsection{Method validation on dried VAMS samples}

\subsubsection{LC-MS/MS analysis}

Optimised mass spectrometer conditions have been obtained by syringe infusion of analyte solutions directly into the ESI source, thus obtaining MS and MS/MS spectra. Quantification was based on the most prominent MRM transition, while a second transition was monitored for qualitative purposes. Table 2 reports quantitative and qualitative transitions, cone voltages, collision energies and retention times for each synthetic cathinone analogue. A suitable chromatographic setup was chosen for the simultaneous separation of the selected 6 cathinone analogues in less than $10 \mathrm{~min}$ and a total run time of $15 \mathrm{~min}$. The use of a highly aqueous composition gradient allowed an effective separation of these rather similar compounds, while a satisfactory sample clean-up process has allowed to improve column lifetime. The best results in terms of peak shape and resolution were obtained by preparing injected solutions in a mixture of $0.1 \%$ FA in acetonitrile and $0.1 \% \mathrm{FA}$ in water $(50 / 50)$.

Fig. 4a-c shows MRM chromatograms of the quantifier transitions for all the 6 analytes in dried blank samples fortified at $100 \mathrm{ng} \mathrm{mL}^{-1}$ after VAMS procedure, in particular Fig. $\mathbf{4 a}$ is referred to urine, Fig. $\mathbf{4 b}$ to plasma and Fig. $4 c$ to oral fluid.

This item was downloaded from IRIS Università di Bologna (https://cris.unibo.it/) 
Table 2 - MRM transitions, retention time, cone voltage, collision energy and IS

\begin{tabular}{|c|c|c|c|c|c|c|}
\hline Analyte & $\begin{array}{c}\text { Q1 } \\
\text { (amu) }\end{array}$ & $\begin{array}{c}\text { Q3 } \\
\text { (amu) }\end{array}$ & $\begin{array}{c}t_{R} \\
(\min )\end{array}$ & $\begin{array}{c}\text { Cone voltage } \\
\text { (V) }\end{array}$ & $\begin{array}{c}\text { Collision energy } \\
\text { (eV) }\end{array}$ & IS \\
\hline \multirow{2}{*}{ Methylone } & \multirow{2}{*}{208.16} & $160.21^{a}$ & \multirow{2}{*}{4.65} & 27 & 15 & \multirow{2}{*}{ Methylone- $\mathrm{D}_{3}$} \\
\hline & & $132.10^{b}$ & & 27 & 27 & \\
\hline \multirow{2}{*}{ Ethylone } & \multirow{2}{*}{222.15} & $204.21^{a}$ & \multirow{2}{*}{5.29} & 27 & 13 & \multirow{2}{*}{ Ethylone-D 5} \\
\hline & & $174.31^{b}$ & & 27 & 19 & \\
\hline \multirow{2}{*}{ Butylone } & \multirow{2}{*}{222.28} & $204.22^{a}$ & \multirow{2}{*}{5.43} & 19 & 11 & \multirow{2}{*}{ Butylone- $D_{3}$} \\
\hline & & $174.32^{b}$ & & 19 & 17 & \\
\hline \multirow{2}{*}{ 4-MMC } & \multirow{2}{*}{178.19} & $160.25^{a}$ & \multirow{2}{*}{5.82} & 23 & 13 & \multirow{2}{*}{$4-M_{M C}-D_{3}$} \\
\hline & & $145.17^{b}$ & & 23 & 19 & \\
\hline \multirow{2}{*}{ 4-MEC } & \multirow{2}{*}{192.23} & $174.30^{a}$ & \multirow{2}{*}{6.10} & 13 & 13 & \multirow{2}{*}{$4-M M C-D_{3}$} \\
\hline & & $143.98^{b}$ & & 13 & 17 & \\
\hline \multirow{2}{*}{ MDPV } & \multirow{2}{*}{276.37} & $135.15^{a}$ & \multirow{2}{*}{7.43} & 29 & 23 & \multirow{2}{*}{ MDPV-D 8} \\
\hline & & $126.21^{b}$ & & 29 & 25 & \\
\hline
\end{tabular}

a Quantifier ion

${ }^{b}$ Qualifier ion

This item was downloaded from IRIS Università di Bologna (https://cris.unibo.it//

When citing, please refer to the published version. 

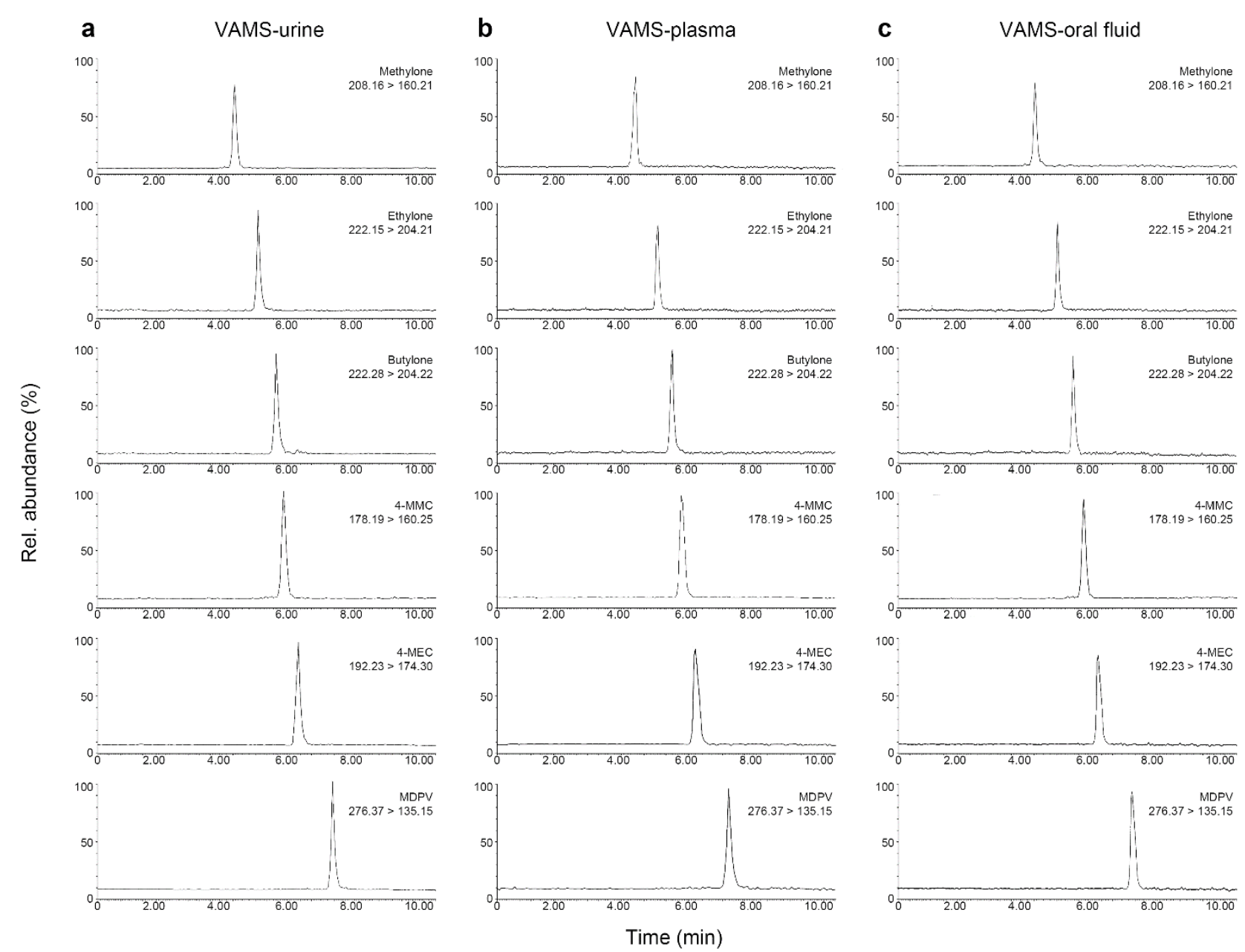

Figure 4 - MRM chromatograms (quantifier transitions) of the six analytes in dried blank samples, fortified at $100 \mathrm{ng} \mathrm{mL} \mathbf{L}^{-1}$, in (a) urine, (b) plasma and (c) oral fluid sampled by VAMS devices.

This item was downloaded from IRIS Università di Bologna (https://cris.unibo.it/)

When citing, please refer to the published version. 


\subsubsection{Linearity and selectivity}

Calibration curves (analyte/IS peak area ratios versus nominal analyte concentrations) were plotted using VAMS calibrators over the range $10-500 \mathrm{ng} \mathrm{mL}^{-1}$ in blank urine, plasma and oral fluid. Linear regression correlation coefficient $\left(\mathrm{R}^{2}\right)$ better than 0.9990 was obtained in all cases (Table 3). Back calculated concentrations of the calibration standards were within $\pm 15 \%$ of the nominal value. The LOQ and the LOD values were $10 \mathrm{ng} \mathrm{mL}^{-1}$ and $3 \mathrm{ng} \mathrm{mL}^{-1}$ for all cathinone analogues in the three dried matrices, thus showing satisfactory method sensitivity.

To assess method selectivity towards endogenous compounds blank samples for each biological matrix obtained from six different healthy volunteers were subjected to sample preparation and analysed. No unexpected interference (peak area $>20 \%$ of the LOQ response for the analytes and $5 \%$ for the ISs) were observed in the MS chromatogram channels, demonstrating a good selectivity of the pretreatment procedure. Moreover, analysis of pure solutions of each analyte and IS showed that all substances can be unequivocally identified simultaneously by their MRM transitions and retention time.

This item was downloaded from IRIS Università di Bologna (https://cris.unibo.it/) 
Table 3 - Linearity

\begin{tabular}{|c|c|c|c|c|c|c|}
\hline \multirow[t]{2}{*}{ Analyte } & \multirow{2}{*}{$\begin{array}{l}\text { Linearity } \\
\text { range } \\
\left(\mathrm{ng} \mathrm{mL}^{-1}\right)\end{array}$} & \multicolumn{2}{|c|}{$\begin{array}{c}\text { Equation } \\
\text { coefficients, } \\
y=a x+b^{a}\end{array}$} & \multirow[t]{2}{*}{$R^{2 b}$} & \multirow[t]{2}{*}{$\begin{array}{c}\text { LOQ } \\
\left.\text { (ng mL } \mathrm{mL}^{-1}\right)\end{array}$} & \multirow[t]{2}{*}{ 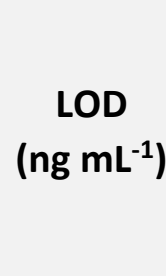 } \\
\hline & & $a^{b}$ & $\mathbf{b}^{\mathrm{b}}$ & & & \\
\hline Methylone & $10-500$ & $\begin{array}{l}31.179 \\
30.998 \\
31.566\end{array}$ & $\begin{array}{r}-17.613 \\
-15.633 \\
-16.231\end{array}$ & $\begin{array}{l}0.9997 \\
0.9999 \\
0.9999\end{array}$ & 10 & 3 \\
\hline Ethylone & $10-500$ & $\begin{array}{l}38.658 \\
36.021 \\
37.133\end{array}$ & $\begin{array}{l}8.362 \\
6.122 \\
7.562\end{array}$ & $\begin{array}{l}0.9991 \\
0.9994 \\
0.9995\end{array}$ & 10 & 3 \\
\hline Butylone & $10-500$ & $\begin{array}{l}37.845 \\
35.542 \\
35.040\end{array}$ & $\begin{array}{l}-25.417 \\
-20.212 \\
-22.311\end{array}$ & $\begin{array}{l}0.9991 \\
0.9996 \\
0.9993\end{array}$ & 10 & 3 \\
\hline 4-MMC & $10-500$ & $\begin{array}{l}39.612 \\
40.502 \\
39.111\end{array}$ & $\begin{array}{l}27.779 \\
25.009 \\
23.665\end{array}$ & $\begin{array}{l}0.9999 \\
0.9991 \\
0.9992\end{array}$ & 10 & 3 \\
\hline 4-MEC & $10-500$ & $\begin{array}{l}29.917 \\
30.855 \\
28.965\end{array}$ & $\begin{array}{l}-11.509 \\
-10.219 \\
-12.146\end{array}$ & $\begin{array}{l}0.9996 \\
0.9995 \\
0.9991\end{array}$ & 10 & 3 \\
\hline MDPV & $10-500$ & $\begin{array}{l}22.590 \\
23.140 \\
22.255\end{array}$ & $\begin{array}{l}-0.0723 \\
-0.0569 \\
-0.0095\end{array}$ & $\begin{array}{l}0.9997 \\
0.9998 \\
0.9999\end{array}$ & 10 & 3 \\
\hline
\end{tabular}

${ }^{a} y=$ analyte peak area; $x=$ analyte concentration, $n g \mathrm{~mL}^{-1}$

${ }^{b}$ The values to linearity parameters on dried urine (first row), plasma (second row) and oral fluid (third row) sampled by VAMS procedure

This item was downloaded from IRIS Università di Bologna (https://cris.unibo.it/)

When citing, please refer to the published version. 


\subsubsection{Absolute recovery, precision and matrix effect}

Absolute recovery and precision were tested on dried blank urine, plasma and oral fluid, spiked with analyte concentrations at 10, 100 and $500 \mathrm{ng} \mathrm{mL}^{-1}$ for each compound (ISs at constant concentration of $100 \mathrm{ng} \mathrm{mL}^{-}$ $\left.{ }^{1}\right)$. The resulting data from extraction recovery assays were satisfactory, being always higher than $75 \%$ for both analytes and ISs. The methodology granted also good precision, with RSD values always lower than 9.0\%. Possible ion suppression or matrix effects were also investigated by injecting blank samples spiked after extraction and comparing the results with those of related standard solutions. The IS-corrected matrix effect results obtained were good, since sample/standard ratios ranged from $93.0 \%$ to $104.9 \%$. All these detailed results are reported in Table 4.

This item was downloaded from IRIS Università di Bologna (https://cris.unibo.it/) 
Table 4 - Precision, absolute recovery and matrix effect

\begin{tabular}{|c|c|c|c|c|c|}
\hline Analyte & $\begin{array}{l}\text { Concentration } \\
\left(\mathrm{ng} \mathrm{mL}^{-1}\right)\end{array}$ & $\begin{array}{l}\text { Intraday } \\
\text { precision } \\
(\mathrm{RSD} \%)^{\mathrm{a}}\end{array}$ & $\begin{array}{l}\text { Interday } \\
\text { precision } \\
\text { (RSD\%) }\end{array}$ & $\begin{array}{c}\text { Absolute } \\
\text { recovery } \\
(\%)^{a}\end{array}$ & $\begin{array}{c}\text { Matrix } \\
\text { effect } \\
(\%)^{a}\end{array}$ \\
\hline \multirow{3}{*}{ Methylone } & 10 & 5.5 & 7.0 & 88.5 & $97.9^{b}$ \\
\hline & 250 & 5.2 & 7.7 & 87.8 & $98.9^{b}$ \\
\hline & 500 & 5.0 & 7.5 & 78.9 & $96.1^{b}$ \\
\hline \multirow{3}{*}{ Ethylone } & 10 & 6.8 & 8.9 & 88.3 & $93.0^{b}$ \\
\hline & 250 & 6.5 & 8.2 & 85.1 & $102.7^{b}$ \\
\hline & 500 & 6.0 & 7.5 & 79.5 & $99.4^{b}$ \\
\hline \multirow{3}{*}{ Butylone } & 10 & 6.1 & 8.7 & 86.3 & $99.0^{b}$ \\
\hline & 250 & 5.9 & 8.5 & 85.6 & $96.2^{b}$ \\
\hline & 500 & 5.5 & 8.0 & 80.9 & $99.3^{b}$ \\
\hline \multirow{3}{*}{ 4-MMC } & 10 & 4.9 & 6.0 & 80.5 & $104.9^{b}$ \\
\hline & 250 & 4.2 & 6.7 & 76.6 & $103.3^{b}$ \\
\hline & 500 & 4.0 & 6.5 & 75.8 & $102.3^{b}$ \\
\hline \multirow{3}{*}{ 4-MEC } & 10 & 6.8 & 8.0 & 75.5 & $103.9^{b}$ \\
\hline & 250 & 6.0 & 7.5 & 75.1 & $103.3^{b}$ \\
\hline & 500 & 5.4 & 7.0 & 76.3 & $99.4^{b}$ \\
\hline \multirow{3}{*}{ MDPV } & 10 & 6.1 & 7.7 & 76.5 & $99.3^{b}$ \\
\hline & 250 & 5.9 & 7.1 & 77.4 & $99.7^{b}$ \\
\hline & 500 & 5.6 & 6.8 & 76.6 & $98.2^{b}$ \\
\hline ISs & 100 & 5.4 & 5.7 & 88.1 & 90.5 \\
\hline
\end{tabular}

This item was downloaded from IRIS Università di Bologna (https://cris.unibo.it/)

When citing, please refer to the published version. 


\subsection{Comparison with wet samples}

Additional calibration and QC samples, at the same concentrations as described for dry VAMSs, were prepared to assay wet matrix samples (fluid plasma, urine and saliva). Comparison methods on wet samples were also validated in terms of linearity, sensitivity, selectivity and precision with good overall results over the selected concentration range (data not shown). The bias values observed between dried VAMS and wet samples were $-6.2,5.8$ and $-5.4 \%$ for urine, plasma and oral fluid, at three level of analyte concentrations. Thus, the sampling/processing methods demonstrated a good equivalence between conventional wet samples and dried samples collected on VAMS devices.

\subsection{Stability}

The mean difference $( \pm S D)$ in chromatographic peak areas between standard solutions of synthetic cathinones (25 $\left.\mathrm{ng} \mathrm{mL}^{-1}\right)$ from stock solutions after controlled storage and standard solution from freshly purchased stock solutions was $-1.5 \%( \pm 0.5)$, indicating a good stability when stored at $-80^{\circ} \mathrm{C}$ for at least 2 months.

Moreover, a stability study of the analytes in dried VAMSs (urine, plasma and oral fluid) was also performed on samples aged for up to 7 days at RT, in the dark and in sealable polyethylene bags containing desiccant packages, giving satisfactory results. The acceptance criterion of $\pm 15 \%$ assay bias was fulfilled for all analytes and ISs.

Since cathinones are susceptible to degradation in wet samples, whereas the degradation process is reduced in DBSs at $4^{\circ} \mathrm{C}$ [28], VAMS sampling strategy could further improve sample stability at RT.

\subsection{Application to real samples and accuracy}

This item was downloaded from IRIS Università di Bologna (https://cris.unibo.it/)

When citing, please refer to the published version. 
Having thus validated the method, it was applied to the analysis of dried plasma, urine and oral fluid VAMS, as well of wet samples, collected from 5 subjects (self-reported users). ISs were added to pooled wet matrices prior to sampling, and all the samples were pretreated following the above described procedure. Concurrent collection of all tested matrices for each subject was not possible. However, the comparison of each dried VAMS sample with the relative wet one was carried out, and the results are summarised in the Table 5. As one can see, the analyte amounts found in VAMS are always in good agreement with those found in wet samples. Application of novel volumetric absorptive microsampling coupled to LC-MS/MS analysis has proven to be effective for the determination of cathinone derivatives in dried samples, thus confirming the obtained validation results.

Moreover, accuracy was evaluated by means of recovery assays. Standard solutions of the analytes at three different concentrations and the ISs at constant concentration were added to already analysed pooled plasma, urine and oral fluid and then subjected to the pretreatment and LC-MS/MS analysis described above. The assays were repeated three times during the same day to calculate mean analyte recovery (\%) and SD values. The results were always $>91 \%( \pm 3.1$ mean SD) for VAMS and $>86 \%$ ( \pm 3.6 mean SD) for plasma. Thus, the method has demonstrated to possess a good accuracy.

This item was downloaded from IRIS Università di Bologna (https://cris.unibo.it/) 
Table 5 - Application to real samples

\begin{tabular}{|c|c|c|c|c|c|c|}
\hline \multirow[b]{3}{*}{ Subject } & \multicolumn{6}{|c|}{ Quali-quantitative results (ng $\mathrm{mL}^{-1}$ ) } \\
\hline & \multicolumn{3}{|c|}{ VAMS sampling } & \multicolumn{3}{|c|}{ Classical wet matrices } \\
\hline & Urine & Plasma & Oral fluid & Urine & Plasma & Oral fluid \\
\hline 1 & N.A. & $\begin{array}{l}\text { Mephedrone } \\
86\end{array}$ & $\begin{array}{l}\text { Mephedrone } \\
40\end{array}$ & N.A. & $\begin{array}{c}\text { Mephedrone } \\
86\end{array}$ & $\begin{array}{c}\text { Mephedrone } \\
38\end{array}$ \\
\hline 2 & $\begin{array}{c}\text { Mephedrone } \\
113\end{array}$ & N.A. & $\begin{array}{c}\text { Mephedrone } \\
18\end{array}$ & $\begin{array}{c}\text { Mephedrone } \\
121\end{array}$ & N.A. & $\begin{array}{c}\text { Mephedrone } \\
15\end{array}$ \\
\hline 3 & $\begin{array}{c}\text { 4-MEC } \\
46 \\
\text { MDPV } \\
148\end{array}$ & $\begin{array}{c}\text { 4-MEC } \\
75 \\
\text { MDPV } \\
56\end{array}$ & N.A. & $\begin{array}{c}\text { 4-MEC } \\
44 \\
\text { MDPV } \\
145\end{array}$ & $\begin{array}{c}\text { 4-MEC } \\
81 \\
\text { MDPV } \\
62\end{array}$ & N.A. \\
\hline 4 & $\begin{array}{c}\text { MDPV } \\
114\end{array}$ & $\begin{array}{l}\text { MDPV } \\
160\end{array}$ & N.A. & $\begin{array}{l}\text { MDPV } \\
115\end{array}$ & $\begin{array}{l}\text { MDPV } \\
160\end{array}$ & N.A. \\
\hline 5 & $\begin{array}{c}\text { 4-MEC } \\
126\end{array}$ & $\begin{array}{c}\text { 4-MEC } \\
49\end{array}$ & $\begin{array}{l}\text { 4-MEC } \\
\text { N.D. }\end{array}$ & $\begin{array}{c}\text { 4-MEC } \\
125\end{array}$ & $\begin{array}{c}\text { 4-MEC } \\
53\end{array}$ & $\begin{array}{l}\text { 4-MEC } \\
\text { N.D. }\end{array}$ \\
\hline
\end{tabular}

This item was downloaded from IRIS Università di Bologna (https://cris.unibo.it/)

When citing, please refer to the published version. 


\section{CONCLUSION}

The present manuscript describes the development and validation of the first VAMS-LC-MS/MS method for quantitative bioanalysis of the main cathinone analogues

(methylone, ethylone, butylone, 4-MMC, 4-MEC and MDPV) in dried matrix samples obtained from urine, plasma and oral fluid. One of the rationales for adopting an innovative miniaturised sampling approach, like VAMS strategy, is to reduce the sampling volume (10 $\mu \mathrm{L})$ and overcome some limitations related to biological fluids of choice in specific settings, such as forensic cases and drug sport testing. In fact, this approach makes the sample collection process fast and feasible, thus simplifying the whole bioanalysis workflow. While the VAMS device is currently commercialised for accurate collection of small blood volumes [13], the study presented herein demonstrates its promising benefits also for other biological matrices.

In this study, ISs have been added to liquid matrix prior to absorption onto the substrate, in order to ensure a full association with matrix components along with the analytes. This could provide more detailed information about the performances of this novel developed VAMS sampling approach. Obviously, in order to set up a methodology that could be applied to on-field sampling and high throughput routine analysis, there is the need to adopt a workflow that does not compromise the advantages of this convenient sampling strategy (e.g. ISs incorporation into the extraction solvent).

VAMS sampling parameters have been tested and optimised, referring to matrix volume, exposure time, drying time, temperature, humidity and light exposure. The device demonstrated to be reliable also when applied to different biological samples, with respect to whole blood, like urine, plasma and oral fluid.

This item was downloaded from IRIS Università di Bologna (https://cris.unibo.it/)

When citing, please refer to the published version. 
The analytical method has been fully validated, showing a good performance in terms of linearity $\left(R^{2}>\right.$ 0.9990), precision (RSD < 9.0\%) and absolute recovery (> 75\%).

The bias values observed between dried VAMS samples and comparison validated methods on wet samples were satisfactory for all the dried matrices, thus demonstrating a good equivalence.

Finally, the method has been successfully applied to the analysis of VAMS and wet samples from self-reported users: the obtained results were in good agreement. Therefore, this LC-MS/MS approach combined to VAMS strategy seems to be promising for future application in forensic cases and sport drug testing. Assays are in progress, in order to apply the method to a larger population with the purpose of drug use monitoring and statistical analysis.

This item was downloaded from IRIS Università di Bologna (https://cris.unibo.it/) 


\section{ACKNOWLEDGMENTS}

This research was financially supported and performed in collaboration with the Commission for the Monitoring and Control of Doping and the Protection of Health in Sporting Activities (Italian Ministry of Health), within the Research project "Innovative sampling and analysis strategies for an effective doping control" (2014-3 CUP J52I14001600005).

The Authors would like to specially acknowledge Major Pietro Della Porta for his useful scientific suggestions.

This item was downloaded from IRIS Università di Bologna (https://cris.unibo.it/)

When citing, please refer to the published version. 


\section{REFERENCES}

[1] http://www.emcdda.europa.eu/publications/drug-profiles/synthetic-cathinones [Accessed on 20 July 2015].

[2] M.H. Baumann, J.S. Partilla, K.R. Lehner, Psychoactive "bath salts": not so soothing, Eur. J. Pharmacol. 698 (2013) 1-5.

[3] Drug Enforcement Administration (DEA), US department of justice, schedules of controlled substances: temporary placement of 10 synthetic cathinones into schedule I. Final order, Fed. Regist. 79 (2014) 12938-12943.

[4] M. Capriola, Synthetic cathinone abuse, Clin. Pharmacol. 5 (2013) 109-115.

[5] https://www.wada-ama.org/en/media/news/2014-09/wada-publishes-2015-prohibited-list [Accessed on 20 July 2015].

[6] N. Sadones, S. Capiau, P.M. De Kesel, W.E. Lambert, C.P. Stove, Spot them in the spot: analysis of abused substances using dried blood spots, Bioanalysis 6 (2014) 2211-2227.

[7] P.M. Edelbroek, J. van der Heijden, L.M. Stolk, Dried blood spot methods in therapeutic drug monitoring: methods, assays, and pitfalls, Ther. Drug Monit. 31 (2009) 327-336.

[8] L. Mercolini, R. Mandrioli, G. Gerra, M.A. Raggi. Analysis of cocaine and two metabolites in dried blood spots by liquid chromatography with fluorescence detection: a novel test for cocaine and alcohol intake, J. Chromatogr. A 1217 (2010) 7242-7248.

[9] L. Mercolini, R. Mandrioli, V. Sorella, L. Somaini, D. Giocondi, G. Serpelloni, M.A. Raggi, Dried blood spots: liquid chromatography-mass spectrometry analysis of $\Delta 9$-tetrahydrocannabinol and its main metabolites, J. Chromatogr. A 1271 (2013) 33-40.

This item was downloaded from IRIS Università di Bologna (https://cris.unibo.it/)

When citing, please refer to the published version. 
[10] P. Denniff, C. Holliman, L. Svensson, N. Weng, S. Patel, Bioanalysis zone: DBS survey results, Bioanalysis 6 (2014) 287-291.

[11] L. Mercolini, R. Mandrioli, M. Protti, A. Conca, L.J. Albers, M.A. Raggi, Dried blood spot testing: a novel approach for the therapeutic drug monitoring of ziprasidone-treated patients, Bioanalysis 6 (2014) 1487-95.

[12] L. Mercolini, M.A. Saracino, M. Protti, Current advances in biosampling for therapeutic drug monitoring of psychiatric CNS drugs, Bioanalysis 15 (2015) 1925-1992.

[13] P. Denniff, N. Spooner, Volumetric absorptive microsampling: a dried sample collection technique for quantitative bioanalysis, Anal. Chem. 86 (2014) 8489-8495.

[14] K.E. Vircks, C.C. Mulligan, Rapid screening of synthetic cathinones as trace residues and in authentic seizures using a portable mass spectrometer equipped with desorption electrospray ionisation, Rapid Commun. Mass Spectrom. 26 (2012) 2665-2672.

[15] P. Jankovics, A. Varadi, L. Tolgyesi, S. Lohner, J. Nemeth-Palotas, H. Koszegi-Szalai, Identification and characterisation of the new designer drug 4-methylethcathinone (4-MEC) and elaboration of a novel liquid chromatography-tandem mass spectrometry (LC-MS/MS) screening method for seven different methcathinone analogs, Forensic Sci. Int. 210 (2011) 213-220.

[16] E. Fornal, Identification of substituted cathinones: 3,4-Methylenedioxy derivatives by high performance liquid chromatography-quadrupole time of flight mass spectrometry, J. Pharm. Biomed. Anal. 81-82 (2013) 13-19.

[17] L. Li, I.S. Lurie, Screening of seized emerging drugs by ultra-high performance liquid chromatography with photodiode array ultraviolet and mass spectrometric detection, Forensic Sci. Int. 237 (2014) 100-111.

This item was downloaded from IRIS Università di Bologna (https://cris.unibo.it/) When citing, please refer to the published version. 
[18] J.P. Smith, J.P. Metters, O.I. Khreit, O.B. Sutcliffe, C.E. Banks, Forensic electrochemistry applied to the sensing of new psychoactive substances: electroanalytical sensing of synthetic cathinones and analytical validation in the quantification of seized street samples, Anal. Chem. 86 (2014) 9985-9992.

[19] S. Gwak, L.E. Arroyo-Mora, J.R. Almirall, Qualitative analysis of seized synthetic cannabinoids and synthetic cathinones by gas chromatography triple quadrupole tandem mass spectrometry, Drug Test Anal. 7 (2015) 121-130.

[20] K. Usui, T. Aramaki, M. Hashiyada, Y. Hayashizaki, M. Funayama, Quantitative analysis of 3,4dimethylmethcathinone in blood and urine by liquid chromatography-tandem mass spectrometry in a fatal case, Leg. Med. (Tokyo) 16 (2014) 222-226.

[21] L.K. Sorensen, Determination of cathinones and related ephedrines in forensic whole-blood samples by liquid-chromatography-electrospray tandem mass spectrometry, J. Chromatogr. B 879 (2011) 727-736.

[22] A. Wohlfarth, W. Weinmann, S. Dresen, LC-MS/MS screening method for designer amphetamines, tryptamines, and piperazines in serum, Anal. Bioanal. Chem. 396 (2010) 24032414.

[23] M.J. Swortwood, D.M. Boland, A.P. DeCaprio, Determination of 32 cathinone derivatives and other designer drugs in serum by comprehensive LC-QQQ-MS/MS analysis, Anal. Bioanal. Chem. 405 (2013) 1383-1397.

[24] M. Mayer, A. Benko, A. Huszár, K. Sipos, A. Lajtai, A. Lakatos, Z. Porpáczy, Simultaneous determination of 4-substituted cathinones (4-MMC, 4-MEC and 4-FMC) in human urine by HPLCDAD, J. Chromatogr. Sci. 51 (2013) 861-866.

This item was downloaded from IRIS Università di Bologna (https://cris.unibo.it/)

When citing, please refer to the published version. 
[25] M. Concheiro, S. Anizan, K. Ellefsen, M.A. Huestis, Simultaneous quantification of 28 synthetic cathinones and metabolites in urine by liquid chromatography-high resolution mass spectrometry, Anal. Bioanal. Chem. 405 (2013) 9437-9448.

[26] S. Strano-Rossi, L. Anzillotti, E. Castrignano, F.S. Romolo, M. Chiarotti, Ultra high performance liquid chromatography-electrospray ionization-tandem mass spectrometry screening method for direct analysis of designer drugs, "spice" and stimulants in oral fluid, J. Chromatogr. A 1258 (2012) $37-42$.

[27] P. Amaratunga, B. Lorenz Lemberg, D. Lemberg, Quantitative measurement of synthetic cathinones in oral fluid, J. Anal. Toxicol. 37 (2013) 622-628.

[28] L. Ambach, A. Hernández Redondo, S. König, W. Weinmann, Rapid and simple LC-MS/MS screening of 64 novel psychoactive substances using dried blood spots, Drug. Test. Anal. (2013) 367-375.

[29] D. Gil, P. Adamowicz, A. Skulska, B. Tokarczyk, R. Stanaszek, Analysis of 4-MEC in biological and nonbiological material-Three case reports, Forensic Sci. Int. 228 (2013) e11-e15.

[30] A. de Castro, E. Lendoiro, H. Fernández-Vega, S. Steinmeyer, M. López-Rivadulla, A. Cruz, Liquid chromatography tandem mass spectrometry determination of selected synthetic cathinones and two piperazines in oral fluid. Cross reactivity study with an on-site immunoassay device, J. Chrom. A 1374 (2014) 93-101.

[31] B.M. Cawrse, B. Levine, R.A. Jufer, D.R. Fowler, S.P. Vorce, A.J. Dickson, J.M. Holler, Distribution of Methylone in Four Postmortem Cases, J. Anal. Toxicol. 36 (2012) 434-439.

This item was downloaded from IRIS Università di Bologna (https://cris.unibo.it/) 
[32] L.J. Marinetti, H.M. Antonides, Analysis of Synthetic Cathinones Commonly Found in Bath Salts in Human Performance and Postmortem Toxicology: Method Development, Drug Distribution and Interpretation of Results, J. Anal. Toxicol. 37 (2013) 135-146.

[33] United States Pharmacopeial Convention, 32th ed., United States Pharmacopeia, Rockville, MD (2009) 734-736.

[34] V.P. Shah, K.K. Midha, J.W.A. Findlay, H.M. Hill, J.D. Hulse, I.J. McGilveray, G.McKay, K.J. Miller, R.N. Patnaik, M.L. Powell, A. Tonelli, C.T. Viswanathan, A.Yacobi, Bioanalytical method validation - a revisit with a decade of progress, Pharm. Res. 17 (2000) 1551-1557. 